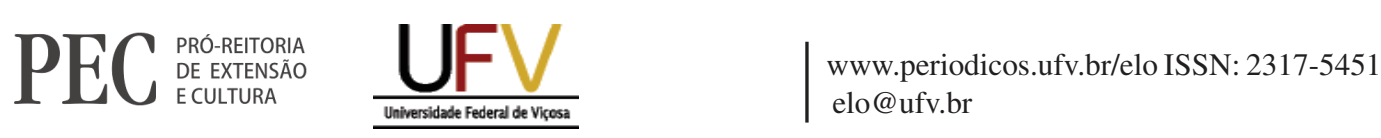

\title{
A utilização de um podcast para disseminação de informações sobre a MP 936/2020: Um relato de experiência
}

\author{
Adriana Moreira Dias ${ }^{1}$, Fabio Oliveira Costa ${ }^{2}$, Dayane Maciel Bezerra de \\ Castro $^{3}$, Hanari Santos Almeida ${ }^{4}$ Beatriz Cilene Mafra Neves Bigeli ${ }^{5}$
}

Resumo: Diversas foram as mudanças causadas pelo novo coronavírus, principalmente quanto a direitos e deveres. Sendo assim, a Universidade Estadual do Tocantins por meio do projeto de extensão "Saúde virtual: a prevenção dentro da sua casa", com objetivo de esclarecer dúvidas, bem como disponibilizar orientações relacionadas à pandemia do novo coronavírus e seus impactos em diversas áreas, promoveu, divulgações e atendimentos de forma online. Este relato de experiência trata-se de ação integrante do projeto vivenciado por acadêmicos e professores na produção de um podcast a respeito da Medida Provisória 936/2020. A metodologia utilizada foi o procedimento de pesquisa bibliográfica apresentado de maneira descritiva, e para criação do podcast houve treinamento de áudio visual. $O$ material foi disponibilizado no site da instituição e obteve 566 visitações. Desta forma, percebe-se que houve a garantia de acesso às informações pertinentes durante o período de pandemia, provocou-se também a vivência e a prática do uso de tecnologias pelos professores e alunos envolvidos.

Palavras-chave: Direito do trabalho. Legislação trabalhista. Medidas provisórias. Tecnologia.

Área Temática: Educação e Trabalho.

\section{The use of a podcast to disseminate information about MP 936/2020: An experience report}

\begin{abstract}
Several were the changes caused by the new coronavirus, mainly regarding rights and duties. Therefore, the State University of Tocantins, through the extension project "Virtual health: prevention within your home", with the objective of clarifying doubts, as well as providing guidelines related to the pandemic of the new coronavirus and its impacts in several areas, promoted, disclosures and assistance online. This experience report is an integral part of the project experienced by academics and teachers in the production of a podcast regarding Provisional Measure 936/2020. The methodology used was the bibliographic search procedure presented in a descriptive way, and for creating the podcast there was audio visual training. The material was made available on the institution's website and received 566 visits. Thus, it is clear that there was a guarantee of access to relevant information during the pandemic period, and the experience and practice of using technologies by the teachers and students involved was also provoked.
\end{abstract}

Keywords: : Labor law. Labor legislation. Provisional measures. Technology.

\footnotetext{
${ }^{1}$ Graduanda em Direito, Universidade Estadual do Tocantins (Unitins) Câmpus Dianópolis/TO. Bolsista Pibiex projeto Saúde Virtual: a prevenção dentro de casa. (63)992478126; e-mail: adriana.md@ unitins.br.

${ }^{2}$ Graduando em Direito, Universidade Estadual do Tocantins (Unitins) Câmpus Dianópolis/TO. Bolsista Pibiex projeto Saúde Virtual: a prevenção dentro de casa.

${ }^{3}$ Docente especialista do curso de Direito, Universidade Estadual do Tocantins (Unitins) Câmpus Paraíso/TO;

${ }^{4}$ Docente especialista do curso de Enfermagem, Universidade Estadual do Tocantins (Unitins) Câmpus Augustinópolis/TO;

${ }^{5}$ Docente especialista do curso de Direito, Universidade Estadual do Tocantins (Unitins) Câmpus Dianópolis/TO;
} 


\section{El uso de un podcast para difundir información sobre MP 936/2020: un informe de experiencia}

Resumen: : Varios fueron los cambios provocados por el nuevo coronavirus, principalmente en cuanto a derechos y deberes. Por ello, la Universidad Estatal de Tocantins a través del proyecto de extensión "Salud virtual: prevención dentro de tu hogar", con el objetivo de aclarar dudas, así como brindar pautas relacionadas con la pandemia del nuevo coronavirus y sus impactos en varias áreas, promovió, divulgaciones y asistencia en línea. Este relato de experiencia es parte integral del proyecto vivido por académicos y docentes en la producción de un podcast sobre la Medida Provisional 936/2020. La metodología utilizada fue el procedimiento de búsqueda bibliográfica presentado de forma descriptiva, y para la creación del podcast se contó con capacitación audiovisual. El material estuvo disponible en el sitio web de la institución y recibió 566 visitas. Así, es claro que hubo garantía de acceso a la información relevante durante el período pandémico, y también se provocó la experiencia y práctica del uso de tecnologías por parte de los docentes y estudiantes involucrados.

Palabras clave: Directo del trabajo. Legislación laboral. Medidas provisionales. Tecnología.

\section{INTRODUÇÃO}

Ainda não se sabe qual a proporção do sistema econômico mundial devido à pandemia provocada pelo novo coronavírus (SARS-CoV-2), pois, muitos países ainda enfrentam uma crise sanitária latente, desta forma, os governantes buscam fomentar medidas que possam amenizar o impacto interno injetando fomentos em diversas áreas.

Para os autores Lima, Buss e Paes-Sousa, (2020, p. 01-03), o ano de 2020 afetou a humanidade em todas as dimensões que esta ocupa e o alto grau de transmissibilidade da Covi-19, teve como facilitador o insucesso dos governantes em conter a circulação de pessoas. Cada país vem desenvolvendo manobras econômicas e administrativas na contenção do vírus e manutenção da economia, no entanto, percebe-se que, todos, mesmo aqueles que possuem aparatos tecnológicos e sanitários disponíveis foram afetados de forma substancial. A doença que nasceu na Ásia, teve lá, grandes dificuldades na sua contenção. Mesmo com estas desproporcionalidades, uma forma de "choque" para os governos do mundo, foram à percepção que o emprego de políticas públicas que visem áreas como a saúde, a economia e a tecnologia devem ser reconfiguradas, para garantir a continuidade dos serviços e, simultâneo, a recuperação da empregabilidade para que o mundo volte ao normal.

É certo que esta realidade trouxe mudanças significativas na vida das pessoas, alterando hábitos e ocasionando novas vivências, dentre essas, a relação com o trabalho. Conforme apresentado pela Organização Mundial do Trabalho (OIT) (2020, p.01), o impacto da pandemia afetou 1,6 bilhão, dos dois bilhões de trabalhadores informais no mundo, sendo que a maioria destes é de unidades econômicas mais vulneráveis.

Essas transformações chegaram ao Brasil de forma severa, e para minimizar o aumento da taxa de desemprego, o Governo Federal, através da Medida Provisória (MP) n 936 de $1^{\circ}$ de abril de 2020 apresentou parâmetros com a finalidade de preservar o vínculo empregatício de trabalhadores com carteira assinada, chamado de Programa Emergencial de Manutenção do Emprego e da Renda (IPEA, 2020, p.09). 
Esta MP foi convertida em Lei no dia 06 de julho de 2020, com o intuito de instituir o programa emergencial de manutenção do emprego e da renda (BRASIL, 2020, online). Quando à época da execução da ação de extensão a mesma ainda se tratava de uma Medida Provisória.

Com intuito de auxiliar na correta interpretação e compartilhamento destas mudanças para a sociedade, a Universidade Estadual do Tocantins (Unitins) através do projeto extensão intitulado “Saúde virtual: a prevenção dentro da sua casa" desenvolveu diversos conteúdos pertinentes durante a pandemia. Para a divulgação dessas informações para a população do Estado do Tocantins, criou-se uma página específica para estes conteúdos serem publicizados, em vídeos, podcasts, cartilhas e lives, além disso, disponibilizou-se uma plataforma de atendimentos para sanar dúvidas da população. O projeto é uma iniciativa financiada pelo Governo do Estado do Tocantins, e os temas abordados possuem caráter interdisciplinar, buscou-se detalhar uma ação específica entre aquelas desenvolvidas no âmbito do projeto.

Dentre os instrumentos utilizados para informar a população do Estado do Tocantins, o presente trabalho tem como objetivo relatar experiência da criação de um podcast sobre a MP/936 que foi disponibilizado no sítio eletrônico da Universidade. Para isso, partiremos da apresentação do projeto de extensão, a caracterização da ação “PODCAST MP/936”, em seguida apresentar as metodologias empregadas, a contextualização do tema e por fim discutir os resultados encontrados.

Antes disso, cabe definir o objeto de estudo que é o podcast, o termo surgiu da união da palavra ipod com broadcast, foi criado pelo desenvolvedor de softwares Adam Curry no ano de 2004, que de início era apresentado como iPodder permitindo o download de transmissões pela internet diretamente ao dispositivo iPod (LOUBACK, 2019, n.p.). A utilização de podcasts em atividades acadêmicas permite pedagogicamente a interação entre grupos e promove também, acessibilidade para diversos públicos das diversas áreas de uma comunidade (MOURA; CARVALHO, 2006, p.90).

Percebe-se a necessidade de adaptação nas formas de ensinagem devido o momento no qual as atividades acadêmicas estão sendo reformuladas, para respeitar o distanciamento presencial destes acadêmicos demanda-se a aplicação de novas tecnologias, que devem ser incorporadas nas ações de caráter educacional, e além disso, essas ações tem um caráter inclusivo e inovador (MOURA; CARVALHO, 2006, p. 107-108).

A criação deste podcast disponibilizou para a comunidade extra universidade, informações sobre a MP/ 936 e os direitos trabalhistas no momento de pandemia, enseja-se que ações como esta, devam ser incentivadas para garantia de democratização do ensino.

\section{OBJETIVOS}

A criação da ação de extensão sobre a MP 936/2020 teve como objetivo disseminar informações sobre as mudanças legislativas e seus impactos nos direitos e deveres do trabalhador, sendo disponibilizada de forma 
virtual à comunidade Tocantinense durante a pandemia do novo coronavírus. A ação foi de caráter educativo, social, científico e tecnológico na área do direito.

\section{METODOLOGIA}

O presente trabalho pauta-se na criação de um podcast sobre a MP/936, através de um projeto de extensão, para isso utilizou-se o método descritivo, construído através de revisão bibliográfica, delimitando-se um roteiro de perguntas previamente formuladas que foram respondidas ao longo do desenvolvimento da ação.

Ométodo descritivo foi utilizado para os autores observarem, registrarem e analisarem os dados correlacionandoos, procurou-se descobrir os fenômenos ocorridos com base na MP/936 e como as ciências se comportam em relação aos fatos da pandemia, no campo do direito do trabalho (CERVO; BERVIAN, 2007, p. 61).

A organização do projeto envolveu os 05 Campus da Unitins e contou com a colaboração de 28 professores e 22 acadêmicos bolsistas dos cursos de serviço social, enfermagem e direito. Integraram o grupo de profissionais do projeto, assistentes sociais, enfermeiras, analista de sistemas, advogadas, psicólogas e pedagogas.

As ações gerais do projeto (vídeos, podcasts, cartilhas e lives) ocorreram semanalmente no site da universidade pelo link: https://www.unitins.br/saudevirtual/. Esta ação em específico foi disponibilizada em formato de podcast em campo específico do site, identificado com o título "PODCAST MP/936".

Houve orientação técnica para os acadêmicos e professores envolvidos, dada pela equipe de tecnologia e mídia da instituição, apresentaram ferramentas para a produção do material de forma clara e objetiva, com o intuito de produção de uma ferramenta de áudio capaz de disponibilizar material de qualidade, fácil compreensão e articulação do conteúdo da MP/936.

Após o processo de criação, o material foi salvo no formato $m p 4$ e encaminhado para emissora de rádio da universidade, que procedeu com a edição final do podcast, formatou o material com a inclusão da vinheta do projeto e realizou ajustes técnicos para garantir a qualidade de som, deixou o material pronto para ser publicado no sítio da instituição.

\section{RESULTADOS E DISCUSSÃO}

Utilizou-se o podcast para a divulgação do conteúdo sobre a MP/936, principalmente pela facilidade de acesso e de reprodução individual e de forma gratuita das informações sobre o tema, pelo site do projeto ou pela plataforma spotify.

Essa ação integra o conjunto de conteúdos que foram desenvolvidos e divulgados em formatos diferenciados, sobre as medidas de enfrentamento do novo coronavírus, a utilização dos podcasts foi da seguinte forma: o primeiro episódio tratou sobre o auxílio emergencial; e o segundo que foi o abordado por esse trabalho, tratou especificamente sobre direitos trabalhistas. A ação tinha como objetivo apresentar a MP/936 que instituiu o programa emergencial de emprego e da renda. 
O material publicado nesse podcast trouxe informações pertinentes sobre a MP/936. Apresentou-se a MP e como ela aborda alterações nos direitos trabalhistas na situação de calamidade pública, permitindo medidas, como a de diminuição na carga horária de trabalho e a suspensão temporária de contratos de trabalho.

O uso de tecnologias para transmissão de informações pelo podcast alcançou um total de 566 visitações no site. Percebe-se que medidas como esta proporcionam a sociedade, acesso a conteúdo fidedigno de forma clara e objetiva, proporcionando que as diversas mudanças que ocorrem no Brasil sejam desembaraçadas e apresentadas pela comunidade acadêmica.

A disponibilização do material na internet, insere-se em um meio cada vez mais utilizado e que permite o acesso de todos a qualquer momento, contribuiu de forma significativa ao levar para a sociedade o conhecimento sobre as alterações trabalhistas previstas na MP/936, que impactam diretamente a vida dos trabalhadores em um momento de crise sanitária.

É possível notar, portanto, que dentro dos preceitos da extensão universitária ao usar novos métodos para disseminação de informações técnicas e científicas, a academia convida a sociedade para entender seus direitos e deveres. Disseminando análises de informações que a instituição produz, "universidade socializa e democratiza o saber científico, de modo, a não se traduzir em privilégio apenas da minoria da população (universitária), mas difundido também à comunidade não acadêmica” (SANTOS, 2010, p. 14).

Entende-se, portanto, que houve impacto dessa ação em relação às políticas de extensão universitária e que o conteúdo da MP/936 tenha sido nesse momento pandêmico, uma forma de continuidade das ações de democratização do saber acadêmico. Com esse podcast lançaram-se entendimentos sobre questões trabalhistas exploradas no campo jurídico.

\section{CONCLUSÕES}

O desenvolvimento de qualquer projeto seguindo as diretrizes da extensão universitária traduz grande esforço de formatação e criação, pois esse conteúdo produzido deve ser divulgado para a comunidade externa, para evolução dos saberes adquiridos. A ação foi criada levando em considerando a facilidade de acesso de uma mídia em formato de áudio, em razão do tempo e disponibilidade das pessoas que poderiam consumir o conteúdo de forma efetiva.

O podcast sobre a MP/936 apresentou grande potencialidade na disseminação de informações no período de pandemia sobre os direitos trabalhistas, no entanto, reflete-se na possibilidade de que seja utilizada em outras ações de extensão como uma proposta educativa.

Sendo assim dentro das práticas extensionistas, verificou-se que houve uma recepção favorável do conteúdo, e que a ação contribuiu com a estrutura do projeto no todo. Ressalta-se que a experiência de criação e divulgação do podcast provocou vivência e prática educativa cidadã por novas tecnologias pelos acadêmicos e professores da Universidade Estadual do Tocantins. 
O trabalho revela que a produção e disponibilização de um podcast em ambiente virtual, foi possível garantir aos interessados o acesso à informação e, ao mesmo tempo, dar conhecimento quanto às alterações legislativas e seus impactos na vida desses sujeitos. Destaque-se, que a MP/936 tutela sobre a preservação do emprego e da renda de quase um milhão de trabalhadores formais no Brasil, sendo provável, desta forma, que a ação relatada nesse trabalho contribuiu para a efetiva proteção e promoção de direitos de interesse de uma população afetada.

\section{REFERENCIAS}

BRASIL. Medida Provisória no 936, de 01 de abril de 2020. Institui o Programa Emergencial de Manutenção do Emprego e da Renda e dispõe sobre medidas trabalhistas complementares para enfrentamento do estado de calamidade pública. (Convertida na Lei n ${ }^{\circ} 4.020$, de 2020). Diário Oficial da República Federativa do Brasil. Brasília, DF: Presidência da República, [2020]. Disponível em: http:// www.planalto.gov.br/ccivil_03/_ato2019-2022/2020/mpv/mpv936.htm. Acesso em: 01 jul. 2020.

BRASIL, Lei $n^{\circ} 14.020$, de 06 de julho de 2020. Institui o Programa Emergencial de Manutenção do Emprego e da Renda. Diário Oficial da República Federativa do Brasil. Brasília, DF: Presidência da República [2020]. Disponível em: http://www.planalto.gov.br/ccivil_03/_ato2019-2022/2020/Lei/L14020.htm. Acesso em: 30 jul. 2020.

CERVO, A.L; BERVIAN, P.A. Metodologia científica. 5 ed. São Paulo: Pearson Prentice Hall, 2002.

HECKSHER, M. D.; FOGUEL, M. N. Nota Técnica n66. Abril de 2020. Benefícios emergenciais aos trabalhadores informais e formais no brasil: estimativas das taxas de cobertura combinadas da lei no 13.982/ 2020 e da medida provisória no 936/2020. Brasília: IPEA, Abril 2020. Disponível em: http:// repositorio.ipea.gov.br/bitstream/11058/9990/1/ NT_66_Disoc_Beneficios\%20emergenciais\%20aos\%20trabalhadores.pdf. Acesso em: 13 jun. 2020.

LIMA, N.V. T.; BUSS, P. M. ; PAES-SOUSA, R. A pandemia de COVID-19: uma crise sanitária e humanitária. Cad. Saúde Pública, Rio de Janeiro, v. 36, n. 7, e00177020, Jun. 2020. Disponível em: http:// cadernos.ensp.fiocruz.br/csp/artigo/1116/a-pandemia-de-covid-19-uma-crise-sanitaria-e-humanitaria. Acesso em: 07 set. 2020. http://dx.doi.org/10.1590/0102-311X00177020

LOUBACK, A. O que é podcast? Saiba tudo sobre os programas de áudio online. 30/12/2019. Globo - G1. Pub. 30 dez. 2019. Disponível em: https://www.techtudo.com.br/noticias/2019/12/o-que-e-podcast-saibatudo-sobre-os-programas-de-audio-online.ghtml. Acesso em: 13 jun. 2020.

MOURA, A. M.; CARVALHO, A. A. A. PODCAST: Potencialidades na Educação. Revista de Ciências e Tecnologias de Informação Prima.com. Porto, 2006, p.88-110, n. 3. 2006. Disponível em: https:// ojs.letras.up.pt/index.php/prismacom/article/view/2112/1945. Acesso em: 07 set. 2020

OIT - ORGANIZAÇÃO INTERNACIONAL DO TRABALHO. (2020). ILO Monitor: COVID-19 and the world of work. Second edition. Updated estimates and analysis. 29 abril 2020. Disponível em: https:// www.ilo.org/wcmsp5/groups/public/—dgreports/—dcomm/documents/briefingnote/wcms_743146.pdf. Acesso em: 13 jun. 2020. 
SANTOS, M. P. Contributos da extensão universitária brasileira à formação acadêmica docente e discente no século XXI: um debate necessário. Revista Conexão UEPG. Ponta Grossa Ponta vol. 6, núm. 1, jandez, 2010.

Submetido em: 02/08/2020 Aceito em: 05/10/2020. 